Supporting Information

\title{
Biocompatible Polymers for the Synthesis of Nanosalts via Supramolecular Ion-Dipole Interaction
}

Sirui Li, " Yang Yang, " and Kun Liu*

State Key Laboratory of Supramolecular Structure and Materials, Jilin

University, Changchun, 130012, P. R. China.

*Corresponding author

*E-mail: kliu@jilu.edu.cn 


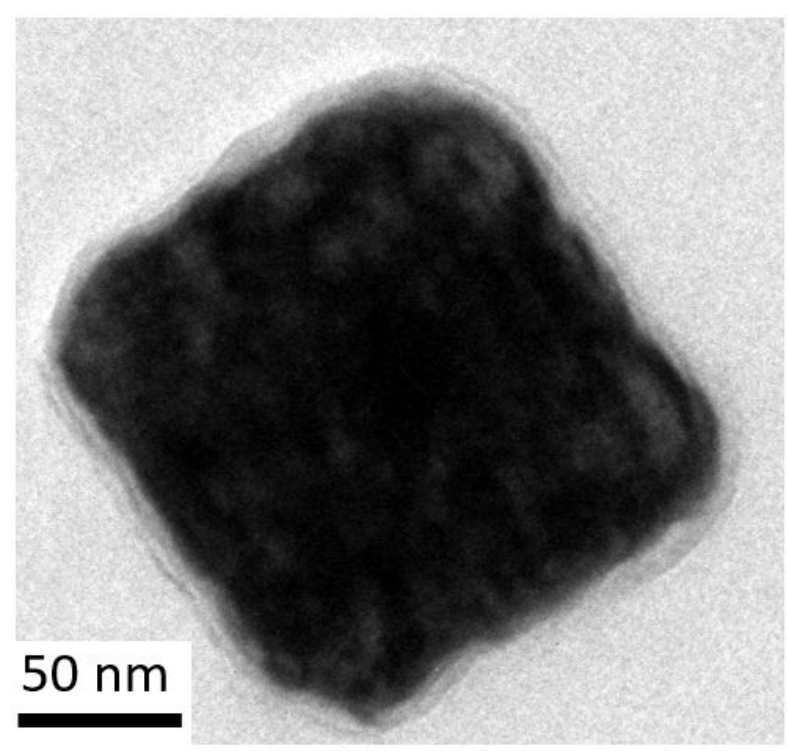

Figure S1. The high resolution TEM image of a nanosalt particle with a layer of PEG surface ligand.

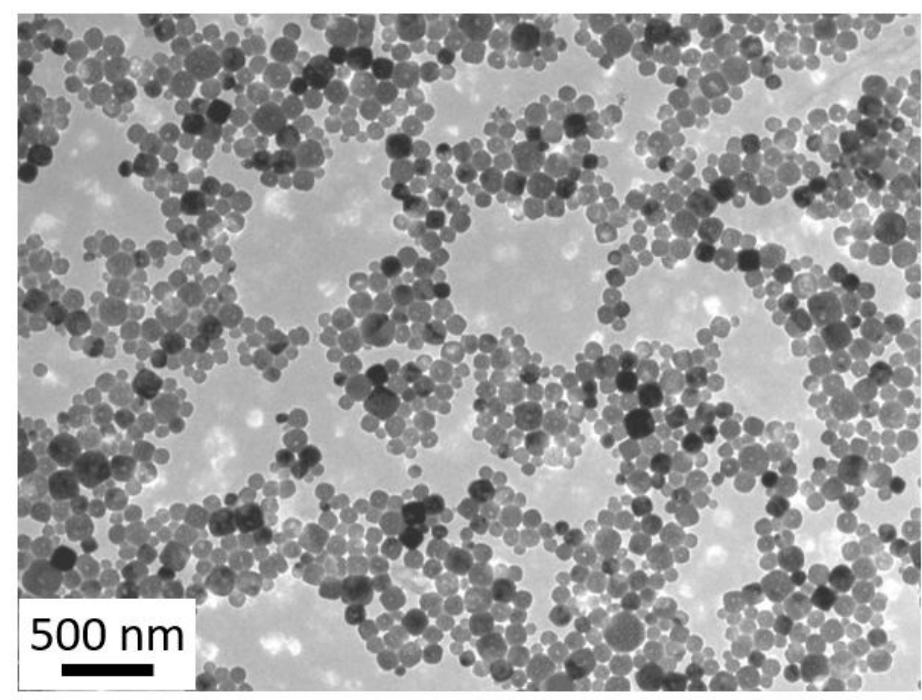

Figure S2. TEM image of $\mathrm{NaCl}$ nanocubes synthesized with food-grade PEG $\left(M_{\mathrm{n}}=10 \mathrm{~kg} / \mathrm{mol}, 100 \mathrm{mg} / \mathrm{mL}\right)$. 
(a)

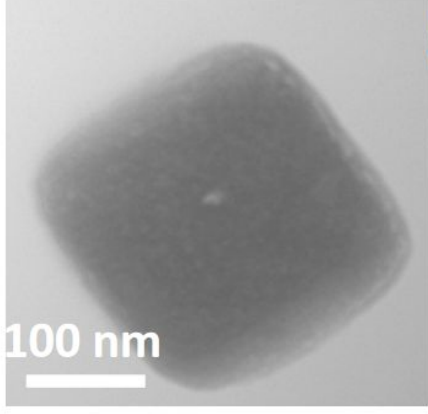

(b)
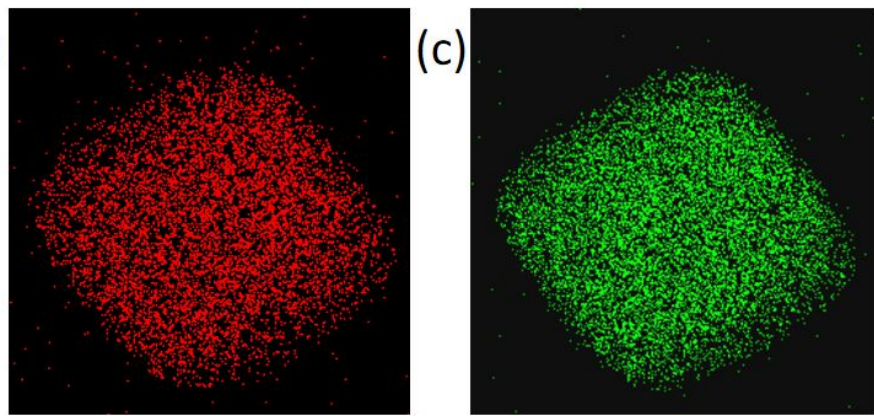

(d)

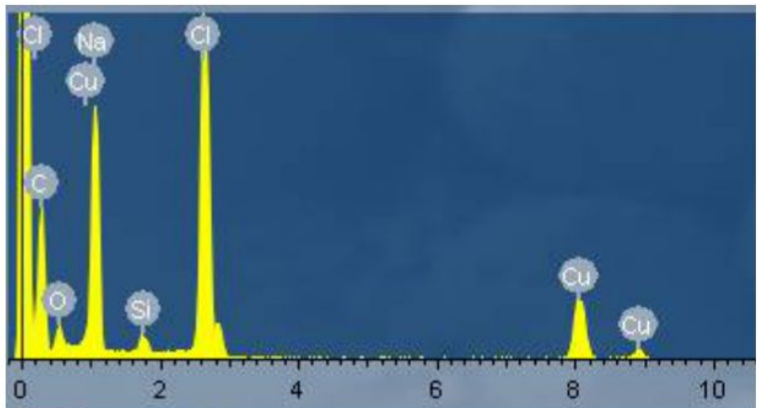

\begin{tabular}{|c|c|c|}
\hline Element & Weight(\%) & Atom(\%) \\
\hline $\mathrm{NaK}$ & 38.38 & 48.99 \\
\hline $\mathrm{Cl} \mathrm{K}$ & 61.62 & 51.01 \\
\hline Total & 100.00 & \\
\hline
\end{tabular}

Figure S3. Mapping and Energy Dispersive Spectroscopy (EDS) analysis of $\mathrm{NaCl} \mathrm{NP}$. (a) HRTEM image of a single $\mathrm{NaCl} \mathrm{NP}$, and corresponding EDS maps of (b) sodium and (c) chlorine. (d) Elementary composition for this whole $\mathrm{NaCl} \mathrm{NP}$ sample. The elements of $\mathrm{Cu}$ and $\mathrm{Si}$ belong to the copper grid. (e) Statistical content for $\mathrm{Na}$ and $\mathrm{Cl}$ elements, with the ratio close to 1:1.

(a)

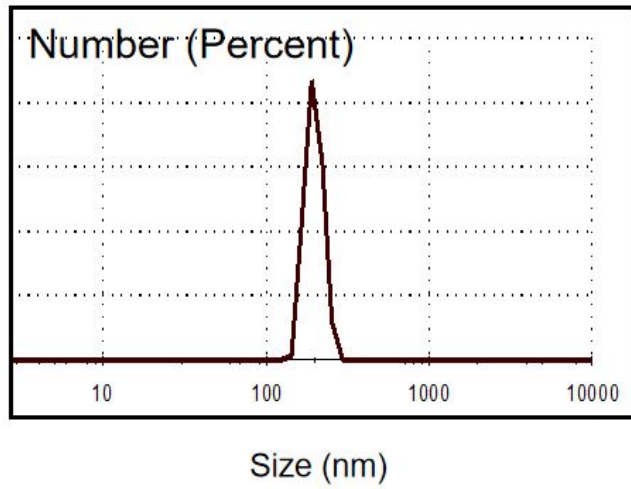

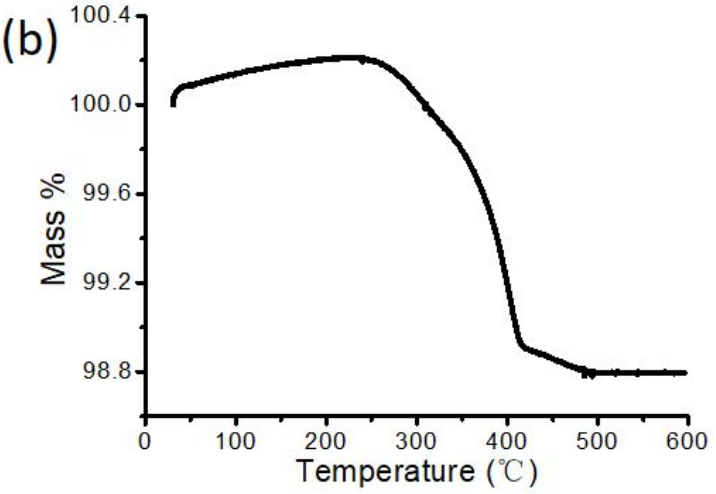

Figure S4. (a) Dynamic light scattering (DLS) data of $\mathrm{NaCl}$ nanosalts@PEG according to number percent, average size of $197.8 \pm 24.8 \mathrm{~nm}$. (b) Thermogravimetric analysis (TGA) data of $\mathrm{NaCl}$ nanosalts@PEG, which mass loss was 1.2\%. 
(a)

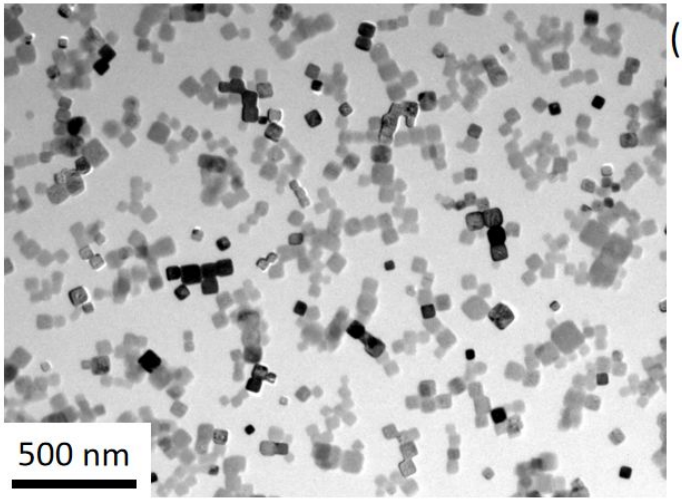

(b)

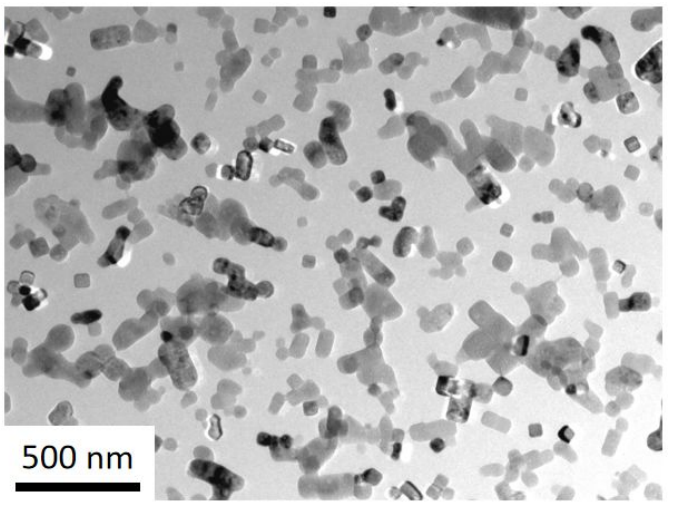

Figure S5. (a) The as-synthesized $\mathrm{NaCl}$ nanoparticles without PEG using the same method and (b) the same sample after $30 \mathrm{~min}$ of storage in the air.

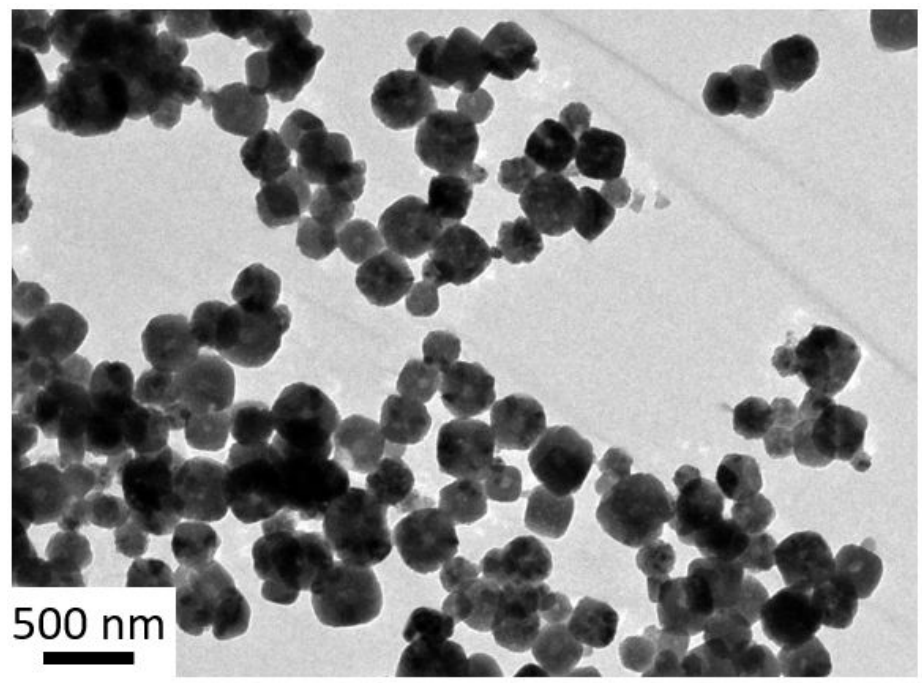

Figure S6. TEM image of $\mathrm{NaCl}$ nanocubes synthesized with PEG $\left(M_{\mathrm{n}}=1.0\right.$ $\mathrm{kg} / \mathrm{mol}, 50 \mathrm{mg} / \mathrm{mL})$. 
(a)

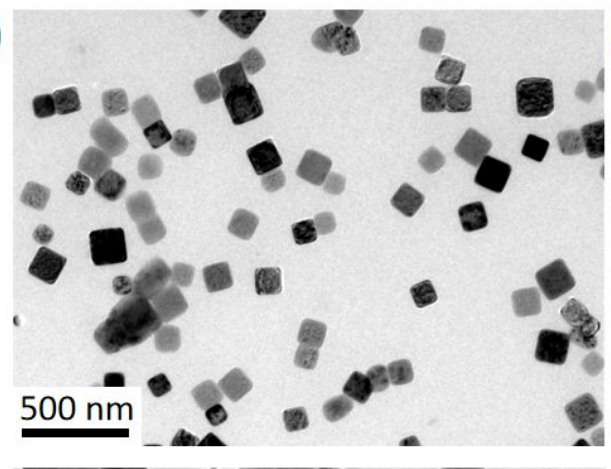

(c)

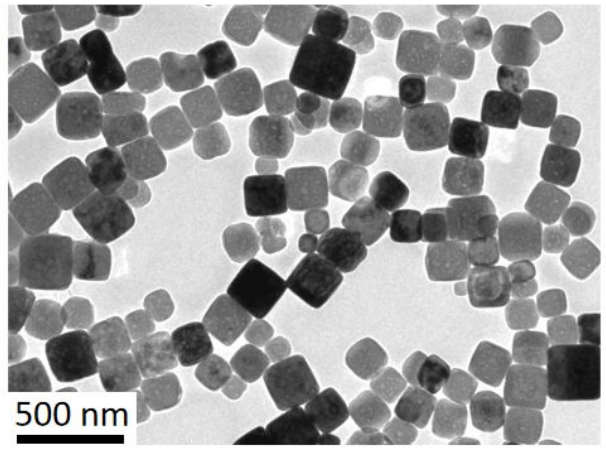

(b)

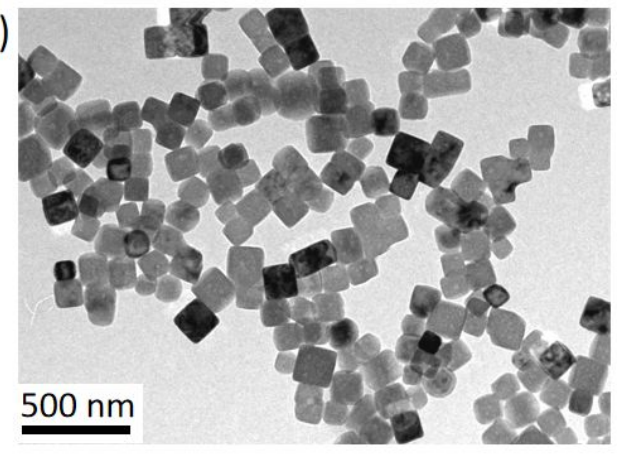

(d)

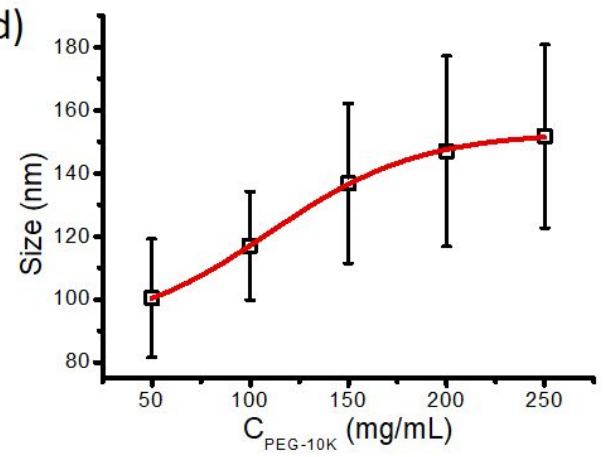

Figure S7. (a)-(c) TEM images of the $\mathrm{NaCl}$ nanocubes synthesized with different concentration of PEG (10 kg/mol): (a) 50, (b) 100, (c) $250 \mathrm{mg} / \mathrm{mL}$, respectively. (d) Size control curve of $\mathrm{NaCl}$ nanocubes with different concentration of PEG.

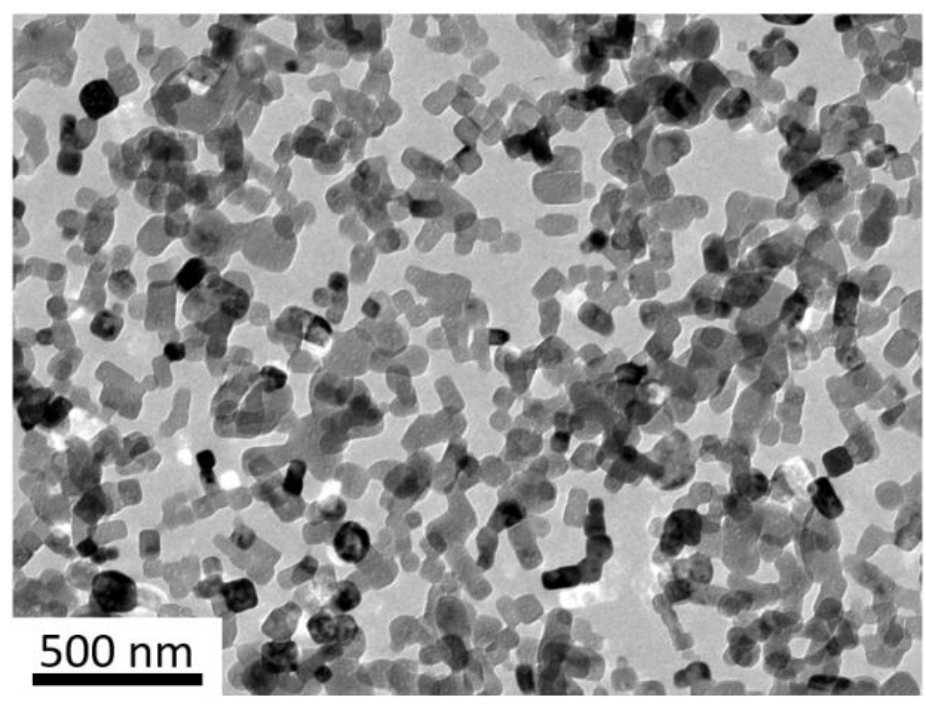

Figure S8. TEM image of $\mathrm{NaCl}$ nanocrystals synthesized with PEG $\left(M_{\mathrm{n}}=10\right.$ $\mathrm{kg} / \mathrm{mol}, 40 \mathrm{mg} / \mathrm{mL})$. 


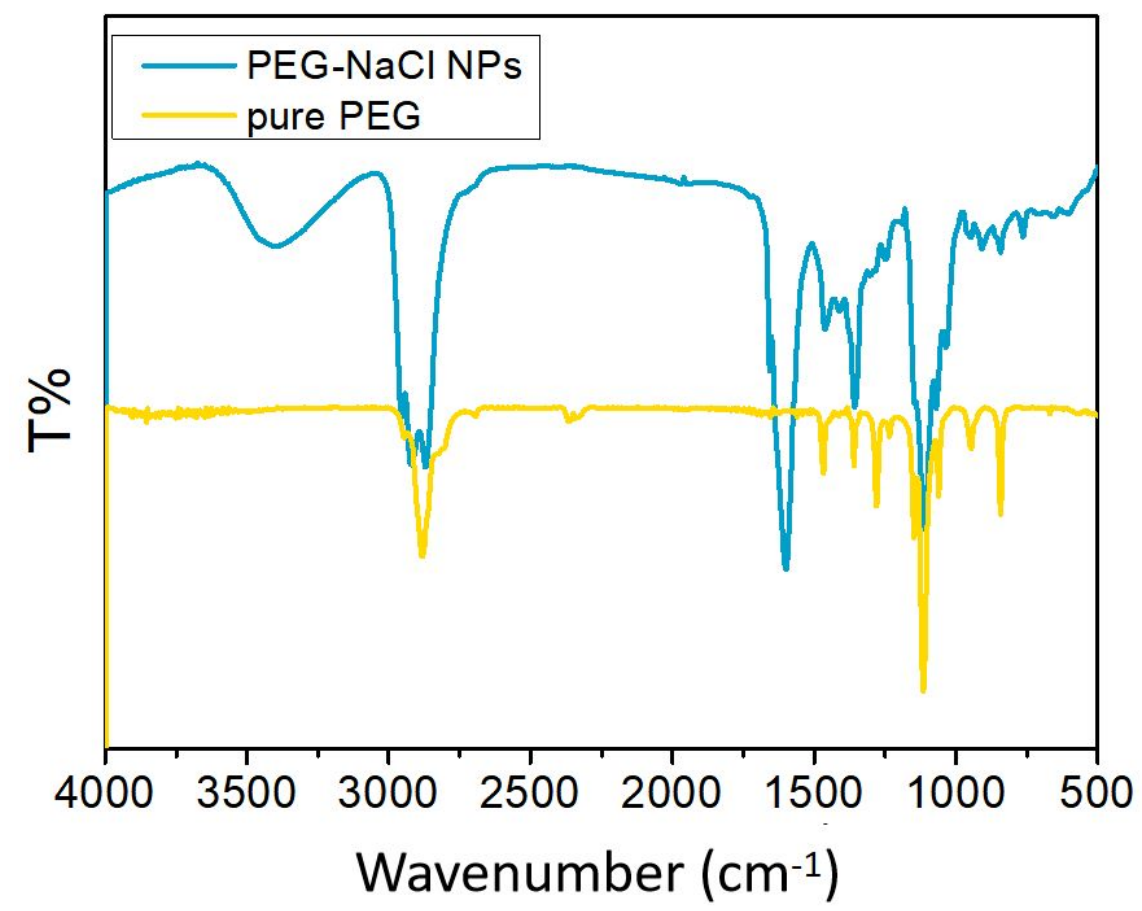

Figure S9. Fourier transform infrared spectroscopy (FTIR) of pure PEG (yellow) and nanosalts@PEG (blue).

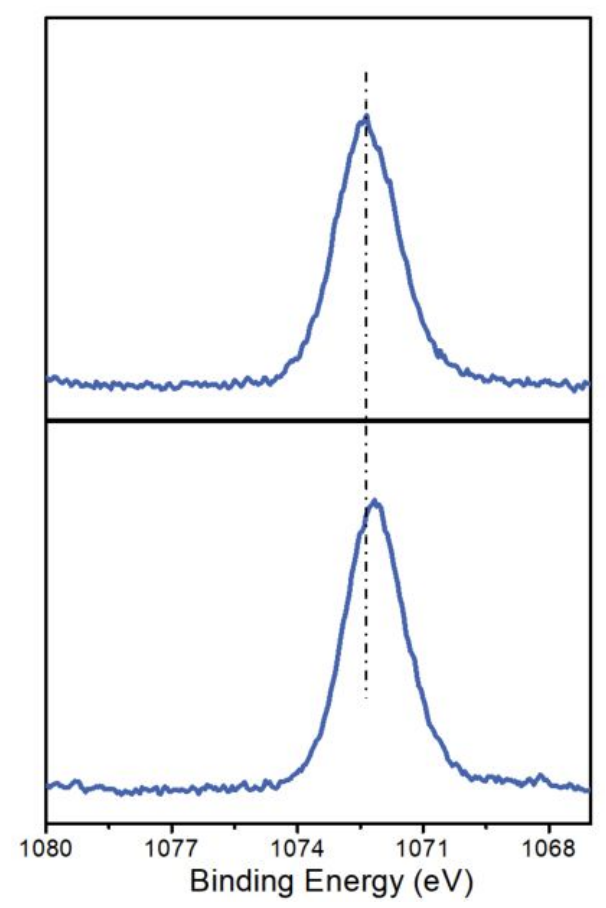

Figure S10. Na 1s X-ray photoeletron spectroscopy (XPS) spectra for pure PEG (top) and nanosalts@PEG (bottom), respectively. 
(a)

(d)
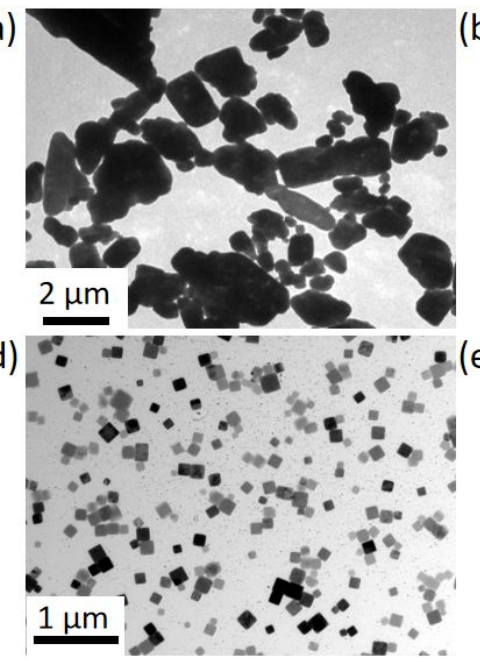

(b)

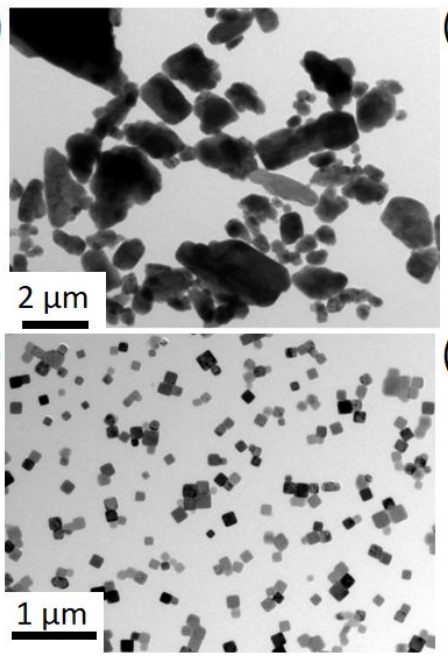

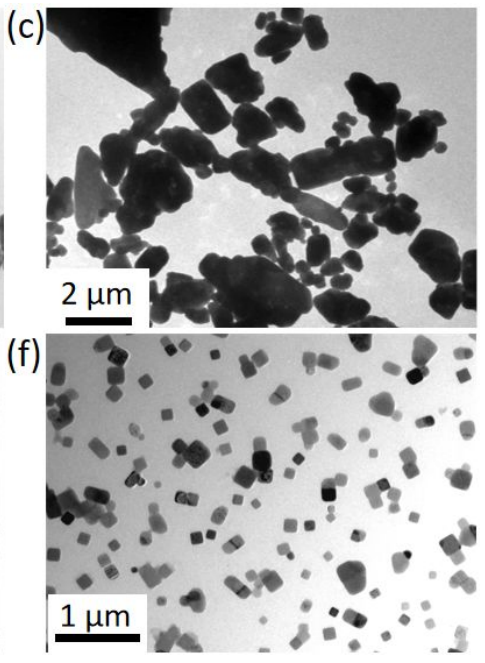

Figure S11. Nanosalts@PEG and grinded micro-sized salts without ligand at the relative humidity $(\mathrm{RH})$ of $43 \%$. (a) micro-sized salts, $0 \mathrm{~h}$, (b) micro-sized salts, $4 \mathrm{~h}$, (c) micro-sized salts, 10 h, (d) Nanosalts@PEG, 0 h, (e) Nanosalts@PEG, 20 h, and (f) Nanosalts@PEG, 116 h.

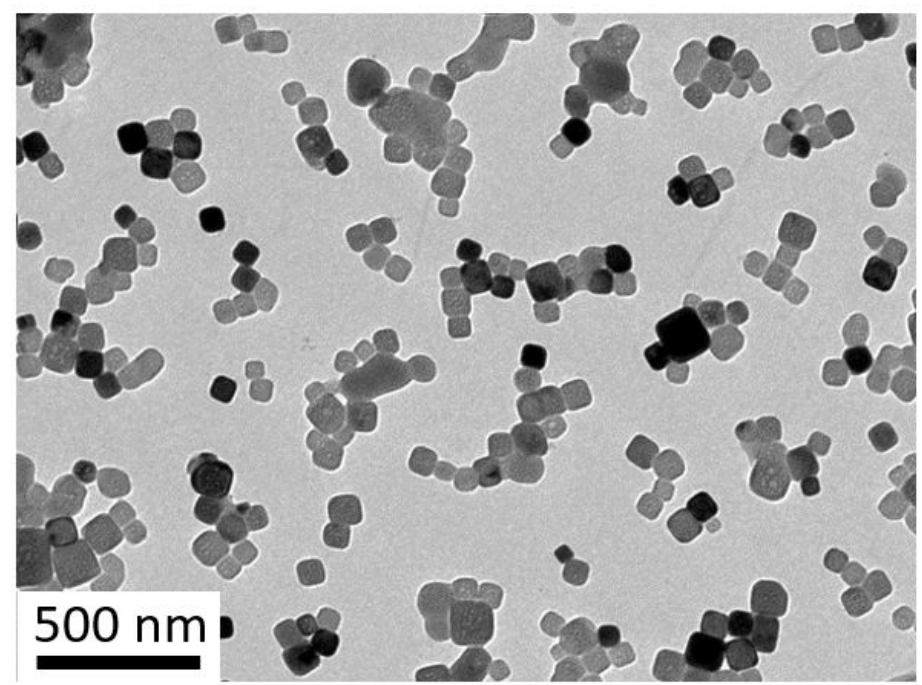

Figure S12. TEM image of $\mathrm{NaCl}$ nanocubes synthesized with $\mathrm{F} 127\left(M_{\mathrm{n}}=12 \mathrm{~kg} / \mathrm{mol}\right.$, $50 \mathrm{mg} / \mathrm{mL})$. 